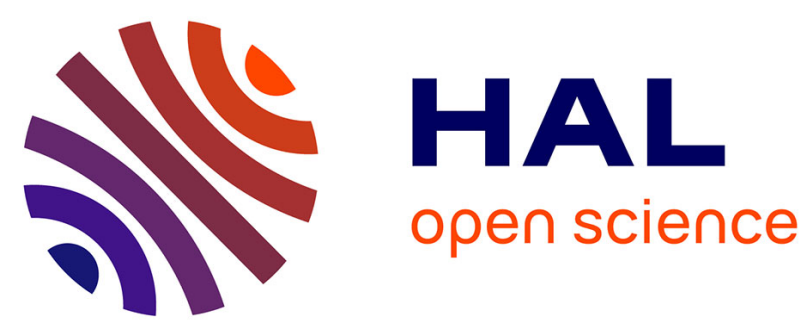

\title{
Safety and Efficacy of 6-thioguanine as a Second-line Treatment for Autoimmune Hepatitis
}

\author{
Clémence Legué, Ludivine Legros, Solène Kammerer-Jacquet, Caroline \\ Jézequel, Pauline Houssel-Debry, Thomas Uguen, Caroline Le Lan, Anne \\ Guillygomarc'H, Romain Moirand, Bruno Turlin, et al.
}

\section{To cite this version:}

Clémence Legué, Ludivine Legros, Solène Kammerer-Jacquet, Caroline Jézequel, Pauline HousselDebry, et al.. Safety and Efficacy of 6-thioguanine as a Second-line Treatment for Autoimmune Hepatitis. Clinical Gastroenterology and Hepatology, 2018, 16 (2), pp.290-291. 10.1016/j.cgh.2017.07.032 . hal-01717742

\section{HAL Id: hal-01717742 \\ https://hal-univ-rennes1.archives-ouvertes.fr/hal-01717742}

Submitted on 29 Mar 2018

HAL is a multi-disciplinary open access archive for the deposit and dissemination of scientific research documents, whether they are published or not. The documents may come from teaching and research institutions in France or abroad, or from public or private research centers.
L'archive ouverte pluridisciplinaire HAL, est destinée au dépôt et à la diffusion de documents scientifiques de niveau recherche, publiés ou non, émanant des établissements d'enseignement et de recherche français ou étrangers, des laboratoires publics ou privés. 


\section{Safety and Efficacy of 6-thioguanine as a Second-line Treatment}

\section{for Autoimmune Hepatitis}

Clémence Legué ${ }^{1}$, Ludivine Legros $^{1}$, Solène Kammerer-Jacquet ${ }^{2,3}$, Caroline Jézequel ${ }^{1}$, Pauline Houssel-Debry ${ }^{1}$, Thomas Uguen ${ }^{1}$, Caroline Le Lan ${ }^{1}$, Anne Guillygomarc' ${ }^{1}$, Romain Moirand ${ }^{1,3}$, Bruno Turlin ${ }^{2}$, Dominique Guyader ${ }^{1,3}$, Edouard Bardou-Jacquet $^{1,3,4}$

${ }^{1}$ CHU Rennes, Department of hepatology, F-35033 Rennes, France

${ }^{2}$ CHU Rennes, Department of anatomopathology, F-35033 Rennes, France

${ }^{3}$ University of Rennes 1, Faculty of Medicine, F-35000 Rennes, France

${ }^{4}$ INSERM, CIC 1414, F-35033 Rennes, France

Short title: 6-thioguanine in autoimmune hepatitis

\section{Corresponding author:}

Edouard Bardou-Jacquet

Department of hepatology, University Medical Center Rennes

2 rue Henri Le Guilloux, 35000 Rennes

E-mail: edouard.bardou-jacquet@univ-rennes1.fr

Fax : +33299284112

Word count: 749

Number of tables: 1 
Abbreviations: AIH: autoimmune hepatitis, EASL: European association for the study of the liver, 6-TG: 6-thioguanine, IBD: inflammatory bowel disease, 6-MP: 6-mercaptopurine, 6TGN: 6 thioguanine nucleotides, NRH: nodular regenerative hyperplasia, IgG: immunoglobulin G, IQR: interquartile range, $\mathrm{PBC}$ : primitive biliary cirrhosis, ASAT: aspartate aminotransferases, ALAT: alanin amino transferase $\gamma$-GT: gammaglutamyl transferase, ALP: alkaline phosphatase, $\gamma$-globulins: gamma-globulins

Conflicts of interest: the authors declare that there is no conflict of interest.

Financial support: none

Author involvement: CL: acquisition of data, analysis and interpretation, drafting of the manuscript. LL: analysis and interpretation, drafting of the manuscript. SFKJ and BT: review of liver biopsy slide, critical review of the manuscript. CJ, PHD, TU, CLL, AG: acquisition of data, critical revision of the manuscrit and material support. RM and DG: critical revision of the manuscript. EBJ: analysis and interpretation, drafting of the manuscript, study supervision. 


\section{Introduction}

Corticosteroids and azathioprine provide complete response with good tolerance in most patients for the treatment of autoimmune hepatitis (AIH). ${ }^{1,2}$ Although some patients require second-line treatments, scarce data and side effects hamper consensus on them. Inflammatory bowel diseases (IBD) yielded increasing consideration for azathioprine metabolism and the use of 6-Mercaptopurine (6-MP) or 6-Thioguanine (6-TG), which both exhibit a more direct metabolism to the active metabolite of azathioprine: 6-thioguanine nucleotides (6-TGN). ${ }^{3}$ Data regarding thiopurines substitution as a second-line therapy for $\mathrm{AIH}$ are limited and even more so regarding 6-TG. We herein report our experience with 6-TG after azathioprine failure or intolerance.

\section{Methods}

Hospital database was searched for adults patients treated with 6-TG for AIH (according to International Autoimmune Hepatitis Group simplified score $\geq 6$ ). Files were reviewed to collect clinical and biological data. 6-thioguanine (20mg/day) was introduced as second or third line therapy because of failure or intolerance to azathioprine.

Because of missing data on IgG during follow-up, efficacy was evaluated on maintained biological response defined by normal serum transaminases after corticosteroids withdrawal. Relapse was defined by an increase of serum transaminases higher than 1.2 times the upper normal range, and/or reintroduction of corticosteroids.

To assess nodular regenerative hyperplasia (NRH) the initial and follow-up liver biopsies (LB) were reticulin stained and reviewed by two pathologists blinded to the patient's data. 


\section{Results}

Seventeen patients were treated with 6-TG, their baseline characteristics are described in Table 1. Discontinuation of azathioprine occurred after 2[1.3-4.2] months because of intolerance (digestive: 11 patients, cutaneous: 3 patients, and haematological: 2 patients), or non-response (1 patient). Eleven patients received 6-TG as second-line therapy. For six patients second-line therapy was mycophenolate mofetil (MMF), but was afterward switched to 6 -TG because of incomplete response ( 5 patients) or intolerance ( 1 patient).

The side effects for which azathioprine was discontinued regressed in all patients after initiation of 6-TG. Sixteen patients had normalization of transaminases within three months, while one patient had to disrupt 6-TG after one month because of dry-eye syndrome. Maintained biological response occurred in 11(64\%) patients. One patient was lost to followup during corticosteroids tapering, and one although responder had anaemia prompting cessation of 6-TG after 13 months. Four patients relapsed, including the patient with previous azathioprine failure. Corticosteroids were reintroduced, with normalization of transaminases and successful tapering for one patient, whereas the 3 others did not responded leading to 6TG cessation and switch for tacrolimus or MMF.

Beside the 2(11\%) patients with dry-eye syndrome and anaemia, no clinical side effects were observed. One patient with cirrhosis had cytopenia that regressed after decreasing 6-TG to $10 \mathrm{mg} /$ day. 
Eight patients had LB after a median 6-TG treatment time of 35[20-52] months. One patient whose LB before 6-TG treatment showed sinusoidal fibrosis and thickening of the hepatic vein wall, showed signs of NRH after 10 months of 6-TG, without clinical portal hypertension. Two patients had worsening fibrosis, one had stopped 6-TG after one month, and one had relapsed.

\section{Discussion}

Azathioprine is the treatment for which long-term data are the most available, ${ }^{1,2}$ therefore treatments based on the same metabolic pathway have a logical relevance. Further, the direct metabolism of 6-TG to 6-TGNs avoids enzymatic variability due to genetic polymorphism, and avoids some metabolites inducing azathioprine intolerance. Moreover, similarly to azathioprine, monitoring of 6-TGN may allows treatment optimization.

MMF is a well described second-line therapy in AIH, which efficacy is $39-71 \%$ in azathioprine intolerant patients. ${ }^{4,5}$ Although comparison is biased, our results with 6-TG show similar success rate $(64 \%)$ with favourable tolerance compared to MMF which induce gastrointestinal side effects in $12-50 \%$ or leukopenia in $7 \%$ of patients. ${ }^{4,5}$

Safety of 6-TG is debated because of NRH. However results are discrepant and NRH even reported without azathioprine treatment. ${ }^{6,7}$ In our study, one of eight patients with LB exhibited NRH. Interestingly some vascular changes existed before 6-TG treatment, which taking into account the short course of treatment received might suggest associated factors. Longer follow-up and larger cohort would be required to assess this issue. 
Hübener et al. recently showed the relevance of 6-MP as a second-line treatment. ${ }^{8}$ Although response rate was similar to our results, the initial side effects recurred in $25 \%$ of patients, whereas in our study they were rarer $(11 \%)$ and differed from those experienced with azathioprine. This may be because contrary to 6-TG, 6-MP still shares metabolites with azathioprine. Interestingly and similarly to our study, non responder to azathioprine neither responded to 6-MP.

In conclusion, our results show that 6-TG could be considered as a relevant option for secondline therapy for AIH in azathioprine intolerant patients. 


\section{References}

1. European Association for the Study of the Liver. EASL Clinical Practice Guidelines: Autoimmune hepatitis. J Hepatol. 2015;63(4):971-1004.

2. Manns MP, Czaja AJ, Gorham JD, et al. Diagnosis and management of autoimmune hepatitis. Hepatology. 2010;51(6):2193-2213.

3. Karran P, Attard N. Thiopurines in current medical practice: molecular mechanisms and contributions to therapy-related cancer. Nat Rev Cancer. 2008;8(1):24-36.

4. Hennes EM, Oo YH, Schramm C, et al. Mycophenolate mofetil as second line therapy in autoimmune hepatitis? Am J Gastroenterol. 2008;103(12):3063-3070.

5. Richardson PD, James PD, Ryder SD. Mycophenolate mofetil for maintenance of remission in autoimmune hepatitis in patients resistant to or intolerant of azathioprine. $\mathrm{J}$ Hepatol. 2000;33(3):371-375.

6. van Asseldonk DP, Jharap B, Verheij J, et al. The Prevalence of Nodular Regenerative Hyperplasia in Inflammatory Bowel Disease Patients Treated with Thioguanine Is Not Associated with Clinically Significant Liver Disease. Inflamm Bowel Dis. 2016;22(9):2112-2120.

7. De Boer NKH, Tuynman H, Bloemena E, et al. Histopathology of liver biopsies from a thiopurine-naïve inflammatory bowel disease cohort: prevalence of nodular regenerative hyperplasia. Scand J Gastroenterol. 2008;43(5):604-608.

8. Hübener S, Oo $\mathrm{YH}$, Than NN, et al. Efficacy of 6-Mercaptopurine as Second-Line Treatment for Patients With Autoimmune Hepatitis and Azathioprine Intolerance. Clin Gastroenterol Hepatol Off Clin Pract J Am Gastroenterol Assoc. 2016;14(3):445-453. 
$\underline{\text { Table 1: Population characteristics }}$

\begin{tabular}{|l|l|}
\hline Age(years) & $54[46-68]$ \\
\hline Sex(F/M) & $11(64.7 \%) / 6(35.3 \%)$ \\
\hline Follow-up time (months) & $20.5[10-51]$ \\
\hline Median AIH score & $6[6-7]$ \\
\hline & F0: $0(0 \%)$ \\
Histological Fibrosis & F1: 6(35\%) \\
& F2: 3(18\%) \\
& F3: 4(23.5\%) \\
& F4: 4(23.5\%) \\
\hline Overlap syndrome & $2(12 \%)$ \\
\hline AST(UI/L) & $538[52-909]$ \\
\hline ALT(UI/L) & $609[285-1564]$ \\
\hline$\gamma$-GT(g/L) & $313[180-528]$ \\
\hline ALP(UI/L) & $162[128-432]$ \\
\hline Total Bilirubin( $\mu$ mol/L) & $41[21.7-111]$ \\
\hline Prothrombin Time(\%) & $90[86-98]$ \\
\hline IgG(g/L) & $15.3[13-21.7]$ \\
\hline$\gamma$-globulins $(\mathrm{g} / \mathrm{L})$ & $15.2[13.2-17]$ \\
\hline Antinuclear antibody $>1 / 80$ & $11(64.7 \%)$ \\
\hline Anti smooth muscle antibody $>1 / 80$ & $8(47 \%)$ \\
\hline
\end{tabular}

Results are expressed as median $\left[25^{\text {th }}-75^{\text {th }}\right.$ percentile] or $n$ (percentage). IgG: immunoglobin G. ASAT: aspartate aminotransferases, ALAT: alanin amino transferase $\gamma$-GT: gammaglutamyl transferase, ALP: alkaline phosphatise. 